\title{
Fear of missing out (FoMO): the relationship between FoMO, alcohol use, and alcohol-related consequences in college students
}

Benjamin C. Riordan, Jayde A. M. Flett, John A. Hunter, Damian Scarf and Tamlin S. Conner

*Correspondence: tconner@psy.otago.ac.nz

\section{CrossMark}

$\leftarrow$ Click for updates

Department of Psychology, University of Otago, New Zealand.

\begin{abstract}
Objective: To examine associations between Fear of Missing Out (FoMO), alcohol use, and negative alcohol-related consequences among college students.

Participants: Participants were two samples of undergraduate students ages 18-25 (Study $1 n=182$; Study $2 n=250$ ).

Methods: In both studies, participants completed the Fear of Missing Out Scale (FoMOs) and the Brief Young Adult Alcohol Consequences Questionnaire (B-YAACQ) in which they reported the number of negative alcohol-related consequences experienced over the past three months. Alcohol was measured retrospectively in Study 1, and prospectively in Study 2 using a 13-day Internet daily diary.

Results: Across both studies, higher FoMOs was associated with experiencing more negative alcohol-related consequences but not overall higher alcohol use. In Study 2, higher FoMOs was also associated with consuming a higher quantity of alcoholic drinks per session.

Conclusion: To reduce alcohol-related harm within the college student population, it may be important to address social factors such as FoMO that may drive people towards riskier behavior surrounding alcohol use.
\end{abstract}

Keywords: FoMO, alcohol, alcohol-related consequences, college students, adolescents

\section{Introduction}

College life is associated with an increase in alcohol use [1,2] and this increase in alcohol use can lead to a number of negative alcohol-related consequences such as blackouts [3], sexual risk taking $[\mathbf{4 , 5}]$, physical aggression [6], and driving while intoxicated $[\mathbf{7}, \mathbf{8}]$. A number of factors have been associated with higher alcohol use and alcohol-related consequences in young adults, for example, sorority or fraternity membership [9], local alcohol outlet density [10], participation in large social events [11-13], and previous experiences with alcohol [7]. However, one previously unmeasured factor that may impact students' drinking is Fear of Missing Out (FoMO) [14].

FoMO refers to the uneasy and often all-consuming sense that friends or others are having rewarding experiences from which one is absent [14-16]. It is characterized by a desire to remain socially connected and may manifest itself as a form of social anxiety $[15,16]$ and has been linked to low levels of mood and life satisfaction [14-16]. While FoMO has garnered widespread attention in the media for several years [15-17], it has only recently come under the scrutiny of academic researchers $[14,18]$. Drawing upon the framework of Self-Determination theory [19-21], to date, the literature has predominantly focused on FoMO as a mediator, linking deficits in psychological needs to negative social networking use $[\mathbf{1 4}, 18]$ and academic motivational styles [18]. More specifically, these studies have found that those higher in FoMO tend to have an unhealthy relationship with social networking sites [14]. For example, these people are more likely to check text messages while driving and use Facebook immediately upon waking, directly before going to sleep, and during college lectures [14]. However, FoMO may have implications beyond social networking or social media use and academic motivation.

One possibility is that FoMO could be a factor contributing to greater alcohol use and a higher rate of negative alcohol-related 
consequences in college students. Large social events and heavy drinking go hand-in-hand in college $[13,22,23]$. Because those higher in FoMO check social media sites more regularly, they may be exposed to more social events involving alcohol. In addition, those higher in FoMO may also have stronger social or conformity motives to consume alcohol (e.g., drinking to be liked, drinking to not feel left out, etc.), which have been associated with heavy drinking in college but not necessarily alcoholrelated consequences [24-27]. FoMO could also be associated with more negative alcohol-related consequences either through higher alcohol use [28-30] or greater willingness to engage in higher risk behaviors (e.g., checking text messages while driving) [14]. That is, to avoid missing out, those higher in FoMO may be more willing to place themselves in risky social situations and contexts (e.g., attending parties at unfamiliar locations).

The aim of the current paper was to investigate the potential relationship between FoMO, alcohol use, and alcohol-related consequences in college students. In two studies, which varied in design, we measured self-reported FoMO, alcohol use, and negative alcohol-related consequences. Study 1 was purely retrospective, with participants reporting their alcohol use over the past month, alcohol-related consequences over the past three months, and trait FoMO. Study 2 was prospective, with participants reporting their alcohol use each day for 13-days using a daily diary procedure, their alcohol-related consequences over the past three months, and their trait FoMO. We hypothesized that students higher in FoMO would consume more alcohol and experience more alcohol-related consequences than those lower in FoMO. We also explored which alcohol-related consequences were related most strongly to FoMO. To our knowledge, this is the first study to investigate the link between FoMO and alcohol use and consequences.

\section{Materials and methods Participants, design and procedure}

The data were collected in two samples of undergraduate college students attending the University of Otago, Dunedin, New Zealand. The University of Otago is a college town with a predominantly undergraduate population, with approximately 15,000 of the 22,000 students completing undergraduate degrees. Study 1 was a cross-sectional study using a convenience sample of 182 students ( $78.6 \%$ women), $18-25$ years old $(M=19.4$, $S D=1.4)$. These students were enrolled in first or second year Psychology classes, which are taken by students studying a number of different majors. The participants were of largely New Zealand European descent (80.8\%; 3.8\% Asian; 6.0\% Māori or Pacific Islander; $7.7 \%$ other; 3 participants did not identify their ethnicity) which reflected the wider university. Participants who expressed interest in the study via the online Department of Psychology participation website (advertised as a study of "student experiences") were sent an email with a hyperlink to the study webpage that included a description of the study, electronic informed consent, and the main survey (measures below). This study was run at the beginning of the second term in the southern hemisphere and was completed by the start of the first week of term on July $7^{\text {th }}, 2014$. Of the 260 emailed, 197 participants began the survey and 182 participants offered enough information to be included in the study (14 participants started the survey but did not proceed past the consent form; 1 did not proceed past demographic questions). Participants from Study 1 were reimbursed with partial course credit.

Study 2 was a daily diary study using a broader sample of 262 students (75.3\% female), $18-25$ years old $(M=19.6, S D=1.8)$. Participants were of largely New Zealand European descent (76\%; 12.2\% Asian; 7.2\% Māori or Pacific Islander; $4.6 \%$ other) and were recruited as part of the 2014 wave of the Daily Life Study, a large interdisciplinary study of the health and well-being of young adults. Participants were recruited from Psychology classes via the Department of Psychology participation website (61.5\% of the entire sample), through word of mouth, flyers, and through advertisement in other classes around the university (38.5\% of the final sample). Participants attended an initial laboratory session to complete a survey with demographic measures and other questionnaires (see measures below). Starting the next day, they completed an Internet daily diary between $3 \mathrm{pm}-8$ pm every day for 13 days that included self-report measures of alcohol use, among other questions not relevant to this report. Study 2 ran from the beginning of the first term in the southern hemisphere and was completed by August $13^{\text {th }}, 2014$. Participants from Study 2 were reimbursed with partial course credit if recruited from the Department of Psychology experimentation program $(n=161)$ or a small cash payment if recruited from the wider university $(n=101)$. Twelve participants of the 262 were excluded from analysis (10 participants dropped out prior to completion of the study; 2 participants completed fewer than 7 diary records).

\section{Measures \\ Demographics}

Demographic data collected included gender, age, and ethnicity.

\section{Fear of Missing Out Scale (FoMOs)[14]}

The FoMOs is a psychometrically valid 10 -item scale that measures individual differences in the experience of the pervasive apprehension that others are engaged in more rewarding activities or social relationships than the self (e.g., "I fear others have more rewarding experiences than me"; "When I miss out on a planned get-together it bothers me", etc.). Participants answered each item on a scale from 1 ("Not at all true of me") to 5 ("Extremely true of me"). A mean FoMOs score was calculated for Study 1 and Study 2 (Cronbach's $\alpha=0.85$ and 0.86 , respectively).

\section{Alcohol use}

In Study 1, the number of drinks consumed by participants was assessed using a modified timeline follow-back (i.e., retrospective) survey. Specifically, participants were asked to "Think of a typical week in the last 30 days for you. Think of what you did, where you lived, what your weekly activities were. Try to accu- 
rately remember how much alcohol you typically drank." For all seven days of the week (Mon-Sun), participants estimated the number of standard drinks consumed. Participants were given definitions of a New Zealand standard drink (e.g., 1 standard drink $=330 \mathrm{ml}[11 \mathrm{oz}]$ can or bottle of $4 \%$ beer/cider; 1 small shot of distilled spirits [30 ml; $1 \mathrm{oz}]$; ready to drink beverages $=1.3$ standard drinks; $440 \mathrm{ml}$ [15 oz] can of beer $=1.5$; and 1 bottle of wine $=8$ standard drinks). From this, we computed three measures of alcohol use: weekly drinking (the total number of drinks added across all seven days), drinking frequency (the number of drinking days divided by seven), and drinking quantity (the average number of drinks per drinking day).

In Study 2, the number of drinks consumed by participants was assessed prospectively using a daily diary. Each day for 13 days, participants were asked to report the "number of standard drinks of alcohol consumed the night before", using the same standard drink guidelines as in Study 1. Previous night's alcohol use was surveyed because the survey was only available between $3 \mathrm{pm}$ and $8 \mathrm{pm}$ each day to reduce reporting while intoxicated. Again, we computed the three estimates of alcohol use outlined above (i.e., weekly drinking, drinking frequency, and drinking quantity).

\section{Brief young adult alcohol consequences question- naire (B-YAACQ)[31]}

In both studies the number of negative alcohol-related consequences experienced over the past 3 months was assessed using the B-YAACQ. The B-YAACQ was developed specifically for college aged students and contains 24 items that assess a range of alcohol-related consequences (e.g., "I have taken foolish risks when I have been drinking"; "While drinking, I have said or done embarrassing things"). Participants were asked to report whether they had experienced any of the 24 consequences in the past 3 months (yes $=1 ;$ no $=0$ for each consequence). A 3 month retrospective timeframe is standard for this measure [31]. The 24 consequences participants had experienced were added to provide a sum of consequences in the past 3 months ranging from 0 to 24 . The B-YAACQ was administered in the main survey for Study 1 and in the initial questionnaire for Study 2.

\section{Results}

Table 1 shows the descriptive statistics for FoMOs mean score, weekly drinking, drinking frequency, drinking quantity, and alcohol-related consequences from Study 1 and Study 2. In both studies, there was no difference between men and women in FoMOs, drinking frequency, or B-YAACQ. However, in both studies men reported consuming more weekly alcoholic drinks than women (Study 1: 11.4 vs. $6.9 ; t(180)=3.001, p=0.042$, unequal variance, Cohen's $d=-0.514$; Study 2: 11.4 vs. $5.9 ; t$ $(248)=3.120, p=0.003$, unequal variance, Cohen's $d=-0.655)$. Men also consumed more drinks per session than women (Study 1: 5.3 vs. $3.4 ; t(180)=2.741, p=0.047$, unequal variance, Cohen's $d=-0.486$; Study 2: 6.4 vs. $4.2 ; t(248)=2.534, p=0.013$, unequal variance, Cohen's $d=-0.493$ ). Forty-two participants ( 7
Table 1. Descriptive statistics for the measured variables in Study 1 and Study 2.

\begin{tabular}{lll}
\hline & $\begin{array}{l}\text { Study 1 } \\
(\mathbf{n = 1 8 2})\end{array}$ & $\begin{array}{l}\text { Study 2 } \\
(\mathbf{n = 2 5 0})\end{array}$ \\
\hline FoMOs Mean & $\begin{array}{l}2.4(0.7) \\
1.0-4.5\end{array}$ & $\begin{array}{l}2.4(0.7) \\
1.0-4.8\end{array}$ \\
\hline Weekly Drinks & $7.6(8.9)$ & $7.2(8.7)$ \\
& $0.0-56.0$ & $0.0-57.0$ \\
\hline Drinking Frequency & $0.2(0.2)$ & $0.2(0.2)$ \\
& $0.0-0.9$ & $0.0-0.8$ \\
\hline Drinking Quantity & $4.6(4.1)$ & $4.7(4.6)$ \\
& $0.0-25.0$ & $0.0-25.0$ \\
\hline B-YAACQ & $5.0(4.5)$ & $5.2(4.6)$ \\
& $0.0-16.0$ & $0.0-18.0$ \\
\hline
\end{tabular}

Note: Mean (Standard Deviation), minimum-maximum. FoMOs=Fear of Missing Out scale; Weekly drinks=total number of standard drinks consumed across Mon-Sun; Drinking frequency=proportion of days per week that alcohol was consumed $(.2 * 7$ days $=1.4$ days/week $)$; Drinking quantity=average number of drinks per drinking day; B-YAACQ=Brief Young Adult Alcohol Consequences Questionnaire.

men and 35 women; $23 \%$ of the sample) from Study 1 and 56 participants ( 15 men and 41 women; $22 \%$ of the sample) from Study 2 consumed no alcohol during the study. Furthermore, 28 participants ( 4 men and 24 women; $15 \%$ of the sample) from Study 1 and 51 participants (11 men and 40 women; 20\% of the sample) from Study 2 experienced no alcohol-related consequences over the last three months.

Table 2 presents the correlations between the FoMOs mean, weekly drinks, drinking frequency, drinking quantity, and BYAACQ. Age and gender were tested as control variables; they did not affect results and are therefore not reported on further. Overall, there was no relationship between FoMOs scores and weekly alcohol use or drinking frequency in either Study 1 or Study 2. There was also no relationship between FoMOs and average drinking session quantity in Study 1; however, there was a significant relationship between FoMOs scores and drinking session quantity in Study 2. Participants higher in FoMO reported consuming more drinks per drinking session (5.4 drinks for +1 SD in FoMOs) compared to participants lower in FoMO (3.9 drinks for -1 SD in FoMOs). FoMOs scores accounted for $2.8 \%$ of the variance in drinking session quantity in Study 2 (equivalent to Cohen's $d$ of 0.339 , a "small" effect). Moreover, in both studies, FoMOs was significantly associated with a higher number of negative alcohol-related consequences participants had experienced in the last three months. Participants higher in FoMO reported significantly more negative consequences (Study $1=5.8$ consequences, Study $2=6.6$ consequences for $+1 \mathrm{SD}$ in FoMOs) than participants lower in FoMO (Study 1=3.6, Study 2=3.2 consequences for people $-1 \mathrm{SD}$ in FoMOs). FoMOs scores accounted for $6.2 \%$ and $9.1 \%$ of the variance in negative alcoholrelated consequences in Study 1 and 2, respectively (equivalent to Cohen's $d$ s of 0.514 and 0.631 , both "medium" effects). 
Table 2. Correlations among fear of missing out (FoMO) scores, the drinking variables, and negative alcohol-related consequences (B-YAACQ) in Study 1 and Study 2.

\begin{tabular}{|c|c|c|c|c|c|c|c|c|}
\hline & \multicolumn{4}{|c|}{ Study $1(n=182)$} & \multicolumn{4}{|c|}{ Study $2(n=250)$} \\
\hline & $\begin{array}{l}\text { FoMOs } \\
\text { mean }\end{array}$ & $\begin{array}{l}\text { Weekly } \\
\text { drinks }\end{array}$ & $\begin{array}{l}\text { Drinking } \\
\text { frequency }\end{array}$ & $\begin{array}{l}\text { Drinking } \\
\text { quantity }\end{array}$ & $\begin{array}{l}\text { FoMOs } \\
\text { mean }\end{array}$ & $\begin{array}{l}\text { Weekly } \\
\text { drinks }\end{array}$ & $\begin{array}{l}\text { Drinking } \\
\text { frequency }\end{array}$ & $\begin{array}{l}\text { Drinking } \\
\text { quantity }\end{array}$ \\
\hline FoMOs Mean & -- & -- & -- & -- & -- & -- & -- & -- \\
\hline Weekly Drinks & -0.014 & -- & -- & -- & 0.092 & -- & -- & -- \\
\hline Drinking Frequency & 0.018 & $0.702^{* *}$ & -- & -- & 0.070 & $0.746^{* *}$ & -- & -- \\
\hline Drinking Quantity & 0.026 & $0.806^{* *}$ & $0.417^{\star *}$ & -- & $0.167^{\star *}$ & $0.752^{\star *}$ & $0.348^{\star *}$ & -- \\
\hline B-YAACQ & $0.249^{\star *}$ & $0.382^{\star *}$ & $0.391^{\star *}$ & $0.399^{* *}$ & $0.301^{\star *}$ & $0.431^{\star *}$ & $0.304^{\star *}$ & $0.513^{\star *}$ \\
\hline
\end{tabular}

Note: ${ }^{*} \mathrm{p}<0.05,{ }^{* *} \mathrm{p}<0.01$; FoMOs=Fear of Missing Out Scale mean; Weekly Drinks=total number of standard drinks consumed across Mon-Sun; Drinking Frequency=proportion of days per week that alcohol was consumed $(0.2 * 7$ days=1.4 days/week); Drinking Quantity=average number of drinks per drinking day; B-YAACQ=Brief Young Adult Alcohol Consequences Questionnaire Sum.

Table 3 shows which alcohol-related consequences correlated significantly with FoMOs (i.e., the correlations between individual B-YAACQ items and FoMOs scores). The consequences with the strongest or most consistent correlations with FoMOs scores are presented at the top of Table 3. In both studies, participants higher in FoMOs were more likely to have reported 'feeling badly about myself', 'said embarrassing things', or 'done impulsive things that [they] later regretted' when drinking. Furthermore, they were more likely to have had 'less energy', 'had a hangover', or have 'not remembered stretches of the night'. In Study 2, a broader university sample than Study 1 , those higher in FoMOs were more likely to have 'taken foolish risks when drinking', 'became rude or obnoxious', and 'drank alcohol on nights that they had not planned'.

\section{Discussion}

Across both studies, representing a total of 432 college students, FoMO was significantly related to an increased incidence of negative alcohol-related consequences. Those more likely to 'fear missing out' reported twice as many instances of alcohol related harm over the past three months (average 5.8 incidents in Study 1 and 6.6 incidents in Study 2) compared to those low in 'fear of missing out' (average 3.6 incidents in Study 1 and 3.2 incidents in Study 2).

The severity of the negative consequences experienced by those higher in FoMO appeared diverse. For example, those higher in FoMO were more likely to have 'said or done something embarrassing' and 'had a hangover. These items are considered mildly severe items on the B-YAACQ (typically experienced by around $87 \%$ of students who drank at least once a week [31]) and experiencing these consequences may be considered typical for college students who drink. However, in both studies, FoMO was also related to items on the B-YAACQ that demonstrate more serious impairments in functioning (e.g., 'felt badly about myself' and 'had less energy because of my drinking'; typically experienced by around $25 \%$ of students who drank at least once a week [31]). Those higher in FoMO also reported more hangover
Table 3. Correlations between Fear of Missing Out (FoMO) scores and each alcohol-related consequence from the B-YAACQ in Study 1 and Study 2.

\begin{tabular}{lll}
\hline & Study 1 & Study 2 \\
\hline Felt badly about myself & $0.330^{\star *}$ & $0.167^{\star *}$ \\
Had less energy & $0.300^{\star *}$ & $0.194^{\star *}$ \\
Said embarrassing things & $0.188^{\star}$ & $0.197^{\star *}$ \\
Done impulsive things I regretted later & $0.162^{\star}$ & $0.168^{\star *}$ \\
Had a hangover morning after & $0.183^{\star}$ & $0.252^{\star *}$ \\
Not been able to remember large stretches & $0.162^{\star}$ & $0.239^{\star *}$ \\
of the night & & \\
Gotten me into sexual situations I later & $0.176^{\star}$ & 0.070 \\
regretted & & \\
Created problems with BF/GF/Spouse & $0.146^{\star}$ & 0.068 \\
parents or other relatives & & \\
Drinking on nights I hadn't planned & 0.040 & $0.171^{\star *}$ \\
Missed class or work & 0.069 & $0.202^{\star *}$ \\
Found I needed larger amounts to get & 0.144 & $0.282^{\star *}$ \\
drunk & & \\
Been overweight because of drinking & 0.124 & $0.257^{\star *}$ \\
Sick to stomach or thrown up & 0.135 & $0.234^{\star *}$ \\
Taken foolish risks when drinking & 0.088 & $0.220^{\star *}$ \\
Neglected obligations & 0.063 & 0.063 \\
Become rude or obnoxious & 0.130 & $0.174^{\star *}$ \\
Passed out & 0.099 & $0.137^{\star}$ \\
Woken up somewhere unexpected & 0.109 & $0.125^{\star}$ \\
Difficult to limit how much I drink & -0.011 & 0.100 \\
Harmed physical appearance & 0.039 & 0.080 \\
Felt I needed a drink before getting up & -0.002 & -0.092 \\
Spent too much time drinking & 0.085 & 0.057 \\
Quality of work has suffered & -0.015 & 0.033 \\
Driven a car & 0.028 & -0.005 \\
\hline & & \\
\hline
\end{tabular}

Note: ${ }^{*} \mathrm{p}<0.05,{ }^{* *} \mathrm{p}<0.01$ 
symptoms (e.g., 'had a hangover'), risk taking consequences (e.g., 'did impulsive things I regretted later'), and social consequences (e.g., 'said embarrassing things').

In contrast, no relationship was found between FoMO and the frequency of alcohol use or the amount of alcohol consumed per week. However, there was a significant relationship between FoMO and drinking quantity per session in Study 2. Those higher in FoMO drank 1.5 standard drinks more in each drinking session than people lower in FoMO. Study 2 was stronger methodologically than Study 1 because it was more representative of the wider student body and participants tracked their alcohol use in 'near to real-time' using a daily diary procedure. It is possible that Study 2 is a more accurate representation of actual drinking quantity per session. Students higher in FoMO may tend to drink more per occasion because they may be driven to have more socially rewarding experiences. Therefore, they may be more likely to drink at social gatherings or parties, or have higher priorities to attend parties which may lead them to drink more per occasion $[32,33]$. Nevertheless, the effect size linking FoMO to drinking quantity per session was small, with a stronger link between FoMO and alcohol related consequences.

Overall, our findings suggest that the relationship between FoMO and alcohol-related consequences are driven by more than patterns of alcohol use alone. This raises the next question in this line of research-what is the mechanism accounting for the relationship between FoMO and negative alcohol-related harm? Although we did not test the mechanisms linking FoMO to alcohol-related consequences, we can speculate given the patterns in our data. Firstly, given that FoMO is inherently social in its nature, it seems plausible that a higher drive for rewarding social experiences may lead those higher in FoMO to take more risks or engage in higher risk drinking activities in order to maximize socialization opportunities (e.g., playing drinking games, drinking in unfamiliar locations, etc.). This may explain why FoMOs scores were related to consequence items that measured risk taking (e.g., 'did impulsive things while drinking I later regretted'). Secondly, those higher in fear of missing out who are motivated by the need for rewarding social experiences may be more sensitive to social information, particularly cues to their social inclusion/exclusion and behaviors that could compromise their social position [34]. In turn, this may lead to an increased number of social alcohol-related consequences (e.g., 'said or did embarrassing things').

\section{Strengths and limitations}

Our study is the first to establish a link between FoMO and alcohol related consequences in college students. However, we did not test the potential mechanisms linking these two behaviors. We speculate that FoMO results in greater risk taking, greater social sensitivity, and possibly a greater need to belong, however, future research will need to test these mediating constructs explicitly. Potential constructs include belonging, self-esteem, mood, anxiety, personality traits (e.g., sensation seeking, extraversion, and neuroticism), social alcohol motives, and risk taking propensities.
A major strength of this study was the use of two samples, the latter of which used a daily diary tracking method for measuring alcohol use. Although daily diaries offer a more accurate measure of alcohol use and allow us to see the fluctuations of alcohol use day to day, research has suggested that retrospective reports of alcohol use are valid [35] and highly correlated with daily diary reports $[36,37]$. We were able to show that the relationship between FoMO and alcohol use consequences did not differ with either method of reporting, although the diary design detected an association between FoMO and alcohol quantity per drinking session. In addition, despite the fact that the timeframe of measures for Study 1 and Study 2 were different (i.e., weekly alcohol use on average from the last month and consequences for the past three months vs. consequences three months prior to the daily diaries), the relationship held across both studies. In order to better explore the relationship between alcohol use, alcohol-related consequences, and FoMO, it will be important for future studies to measure alcohol use and alcohol-related consequences from the same period of time.

Finally, men were under represented in both studies. Although we found no difference in FoMOs scores between men and women, or any difference in the relationship between FoMOs and alcohol related consequences when controlling for gender, there are known differences between men and women's alcohol use $[12,13]$. Because men and women typically consume different amounts of alcohol, future research testing potential mechanisms underlying the link between FoMO and consequences should ensure both men and women are equally represented.

\section{Conclusions}

FoMO is a risk factor for experiencing alcohol-related harm in college students. Our study showed that those who fear missing out were more likely to exhibit risky behavior when they drank alcohol. Therefore, it may be important to address factors like FoMO in order to reduce alcohol-related harm within the student population, especially at times of the year when social events are particularly salient (e.g., Orientation/Freshers'/Welcome Week).

\section{Competing interests}

The authors declare that they have no competing interests.

\section{Authors' contributions}

Benjamin C. Riordan co-conceived the study idea, co-wrote the manuscript, contributed to the data collection, and conducted the statistical analyses. Jayde A. M. Flett co-conceived the study idea, co-wrote the first draft of the manuscript, managed the data collection, contributed to the study protocol, and revised the drafts of the manuscript. John A. Hunter provided scope and guidance for the article. Damian Scarf contributed to the writing of the manuscript and provided the direction and scope for the article. Tamlin S. Conner designed the study and wrote the protocol, conducted the statistical analyses with BCR, contributed to the writing of the manuscript, and provided funding for the study. All authors contributed to and have approved the final manuscript.

\section{Acknowledgement and funding}

This research was funded by a grant to Tamlin S. Conner 
from the Health Research Council of New Zealand (12/709).

The authors acknowledge members of the 2014 Daily

Experiences Laboratory for their help with data collection.

We also thank Hadyn Youens for web programming.

\section{Publication history}

Vinay Parikh, Temple University, USA.

Received: 28 September 2015 Revised: 29 October 2015

Accepted: 10 November 2015 Published: 19 November 2015

\section{References}

1. Baer JS, Kivlahan DR and Marlatt GA. High-risk drinking across the transition from high school to college. Alcohol Clin Exp Res. 1995; 19:5461. | Article | PubMed

2. Johnston L.D, O'Malley P.M and Bachman J.G. Monitoring the Future: National Survey Results on Drug Use, 1975-1999 Ages 19-40. Bethesda, MD: National Institute on Drug Abuse. US Dept of Health and Human Services. 2:2000.

3. McGee R and Kypri K. Alcohol-related problems experienced by university students in New Zealand. Aust N Z J Public Health. 2004; 28:321-3. | Article | PubMed

4. Cashell-Smith ML, Connor JL and Kypri K. Harmful effects of alcohol on sexual behaviour in a New Zealand university community. Drug Alcohol Rev. 2007; 26:645-51. | Article | PubMed

5. Connor J, Psutka R, Cousins K, Gray A and Kypri K. Risky drinking, risky sex: a national study of New Zealand university students. Alcohol Clin Exp Res. 2013; 37:1971-8. | Article | PubMed

6. Kypri K, Paschall MJ, Langley J, Baxter J, Cashell-Smith M and Bourdeau B. Drinking and alcohol-related harm among New Zealand university students: findings from a national Web-based survey. Alcohol Clin Exp Res. 2009; 33:307-14. | Article | PubMed

7. Hingson R, Heeren T, Zakocs R, Winter M and Wechsler H. Age of first intoxication, heavy drinking, driving after drinking and risk of unintentional injury among U.S. college students. J Stud Alcohol. 2003; 64:23-31. | Article | PubMed

8. Perkins HW. Surveying the damage: a review of research on consequences of alcohol misuse in college populations. J Stud Alcohol Suppl. 2002; 91-100. | Article | PubMed

9. Lo CC and Globetti G. The facilitating and enhancing roles Greek associations play in college drinking. Int J Addict. 1995; 30:1311-22. | PubMed

10. Kypri K, Bell ML, Hay GC and Baxter J. Alcohol outlet density and university student drinking: a national study. Addiction. 2008; 103:11318. | Article | PubMed

11. Lam T, Liang W, Chikritzhs T and Allsop S. Alcohol and other drug use at school leavers' celebrations. J Public Health (Oxf). 2014; 36:408-16. | Article I PubMed

12. Riordan BC, Conner TS, Flett JA and Scarf D. A Brief Orientation Week Ecological Momentary Intervention to Reduce University Student Alcohol Consumption. J Stud Alcohol Drugs. 2015; 76:525-9. | Article | PubMed

13. Riordan BC, Scarf D and Conner TS. Is orientation week a gateway to persistent alcohol use in university students? A preliminary investigation. J Stud Alcohol Drugs. 2015; 76:204-11. | Article I PubMed

14. Przybylski A.K, Murayama K, DeHaan C.R and Gladwell V. Motivational, emotional, and behavioral correlates of fear of missing out. Comput Human Behav. 2013; 29:1841-8.

15. Anderson H. Never heard of Fomo? You're so missing out. The Guardian. 2011.

16. Cohen C. FoMo: Do you have a Fear of Missing Out? The Telegraph. 2013.
17. Chen C. The Fear of Missing Out and how it's killing you. The Huffington Post. 2014.

18. Alt D. College students' academic motivation, media engagement and fear of missing out. Comput Human Behav. 2015; 49:111-9. I Article

19. Deci E.L and Ryan R.M. Intrinsic motivation and self-determination in human behavior. New York: Plenum. 1985.

20. Thogersen-Ntoumani C, Ntoumanis $\mathrm{N}$ and Nikitaras $\mathrm{N}$. Unhealthy weight control behaviours in adolescent girls: a process model based on self-determination theory. Psychol Health. 2010; 25:535-50. | Article | PubMed

21. Ryan RM and Deci EL. Self-determination theory and the facilitation of intrinsic motivation, social development, and well-being. Am Psychol. 2000; 55:68-78. | Article | PubMed

22. Sher KJ, Bartholow BD and Nanda S. Short- and long-term effects of fraternity and sorority membership on heavy drinking: a social norms perspective. Psychol Addict Behav. 2001; 15:42-51. | Article I PubMed

23. Carey KB. Heavy drinking contexts and indices of problem drinking among college students. J Stud Alcohol. 1995; 56:287-92. | Article | PubMed

24. LaBrie JW, Hummer JF and Pedersen ER. Reasons for drinking in the college student context: the differential role and risk of the social motivator. J Stud Alcohol Drugs. 2007; 68:393-8. | Article | PubMed Abstract | PubMed FullText

25. Stewart SH and Chambers L. Relationships between drinking motives and drinking restraint. Addict Behav. 2000; 25:269-74. | Article | PubMed

26. Stewart SH, Zeitlin SB and Samoluk SB. Examination of a threedimensional drinking motives questionnaire in a young adult university student sample. Behav Res Ther. 1996; 34:61-71. | Article | PubMed

27. Wood MD, Read JP, Palfai TP and Stevenson JF. Social influence processes and college student drinking: the mediational role of alcohol outcome expectancies. J Stud Alcohol. 2001; 62:32-43. | Article | PubMed

28. Martens MP, Neighbors C, Lewis MA, Lee CM, Oster-Aaland L and Larimer $M E$. The roles of negative affect and coping motives in the relationship between alcohol use and alcohol-related problems among college students. J Stud Alcohol Drugs. 2008; 69:412-9. | Article | PubMed Abstract | PubMed FullText

29. Park CL and Grant C. Determinants of positive and negative consequences of alcohol consumption in college students: alcohol use, gender, and psychological characteristics. Addict Behav. 2005; 30:75565. | Article | PubMed

30. Simons JS, Gaher RM, Correia CJ, Hansen CL and Christopher MS. An affective-motivational model of marijuana and alcohol problems among college students. Psychol Addict Behav. 2005; 19:326-34. | Article | PubMed

31. Kahler CW, Strong DR and Read JP. Toward efficient and comprehensive measurement of the alcohol problems continuum in college students: the brief young adult alcohol consequences questionnaire. Alcohol Clin Exp Res. 2005; 29:1180-9. | Article | PubMed

32. Sher KJ and Rutledge PC. Heavy drinking across the transition to college: predicting first-semester heavy drinking from precollege variables. Addict Behav. 2007; 32:819-35. I Article I PubMed Abstract | PubMed FullText

33. Wechsler H, Dowdall GW, Davenport A and Castillo S. Correlates of college student binge drinking. Am J Public Health. 1995; 85:921-6. | PubMed Abstract | PubMed FullText

34. Gardner W.L, Pickett C.L and Brewer M.B. Social exclusion and selective memory: How the need to belong influences memory for social events. Pers Soc Psychol Bull. 2000; 26:486-96.

35. Del Boca FK and Darkes J. The validity of self-reports of alcohol 
consumption: state of the science and challenges for research. Addiction. 2003; 98 Suppl 2:1-12. | PubMed

36. Leigh BC, Gillmore MR and Morrison DM. Comparison of diary and retrospective measures for recording alcohol consumption and sexual activity. J Clin Epidemiol. 1998; 51:119-27. | Article | PubMed

37. Patrick ME and Lee CM. Comparing numbers of drinks: college students' reports from retrospective summary, followback, and prospective daily diary measures. J Stud Alcohol Drugs. 2010; 71:554-61. | Article | PubMed Abstract | PubMed FullText

\section{Citation:}

Riordan B. C, Flett J.A.M, Hunter J.A, Scarf D and Conner T.S. Fear of missing Out (FoMO): the relationship between FoMO, alcohol use, and alcohol-related consequences in college students. J Psychiatry Brain Funct. 2015; 2:9.

http://dx.doi.org/10.7243/2055-3447-2-9 